loin katsojissa pyritään herättämään myötätuntoa pakenevia olentoja kohtaan. Elokuvissa käytetty positiiviseksi miellettävä esittämistapa ei ole kuitenkaan Dittmerin mukaan ongelmaton, sillä tällaiset kuvaukset feminisoivat pakolaishahmot ja esittivät nämä vailla mahdollisuuksia omaan toimijuuteen.

Kokonaisuudessaan kaksipäiväinen seminaari loi mielenkiintoisen katsauksen kulttuurintutkimuksen tarjoamiin mahdollisuuksiin tarkastella entisissä Neuvostoliiton maissa toistuvia tapoja käsitellä omaa geopoliittista asemaa. Omat kysymyksensä geopoliittisista narratiiveista puhuttaessa tuntui luovan eri väestöryhmien alati lisääntyvä kansallisvaltioiden väliset rajat ylittävä migraatio. Lievästä Venäjäpainotteisuudestaan huolimatta seminaariin oli onnistuttu saamaan tiivis mutta monipuolinen kattaus erilaisia näkökulmia ja lähestymistapoja. Rajatun kokoinen seminaari toimi hyvin myös formaattina, sillä se tarjosi mahdollisuuden joustavampaan aikatauluun, jolloin pienet tietotekniset vaikeudetkaan eivät syöneet tilaa sessioiden päätteeksi syntyneiltä keskusteluilta.

Eeva Kuikka

\title{
Postereita ja teknopuhetta Aleksanteri-konferenssissa 2019
}

Lokakuun 23.-25. Helsingin yliopistolla kokoontui jälleen vuotuinen Aleksanteri-konferenssi. Konferenssin teema oli teknologia, kulttuuri ja yhteiskunta Euraasian alueella. Konferenssi järjestettiin jo yhdeksännentoista kerran ja se onkin muodostunut tärkeäksi vuotuisten kohtaamisten paikaksi Venäjän, Itä-Euroopan ja Euraasian alueeseen keskittyvälle monitieteiselle tutkijayhteisölle. Perinteisesti Aleksanteri-konferenssi tuo Helsinkiin runsaan joukon tutkijoita kautta maailman, tänä vuonna yhteensä kolmestakymmenestä eri maasta. Kaikkiaan yli puolet tämän vuoden noin kolmestasadasta osallistujista olivat ulkomaisista organisaatioista, erityisesti Venäjältä.

Ohjelma sisälsi yli viisikymmentä paneelia, joiden lisäksi konferenssiväelle tarjottiin mahdollisuus osallistua esimerkiksi opaste-

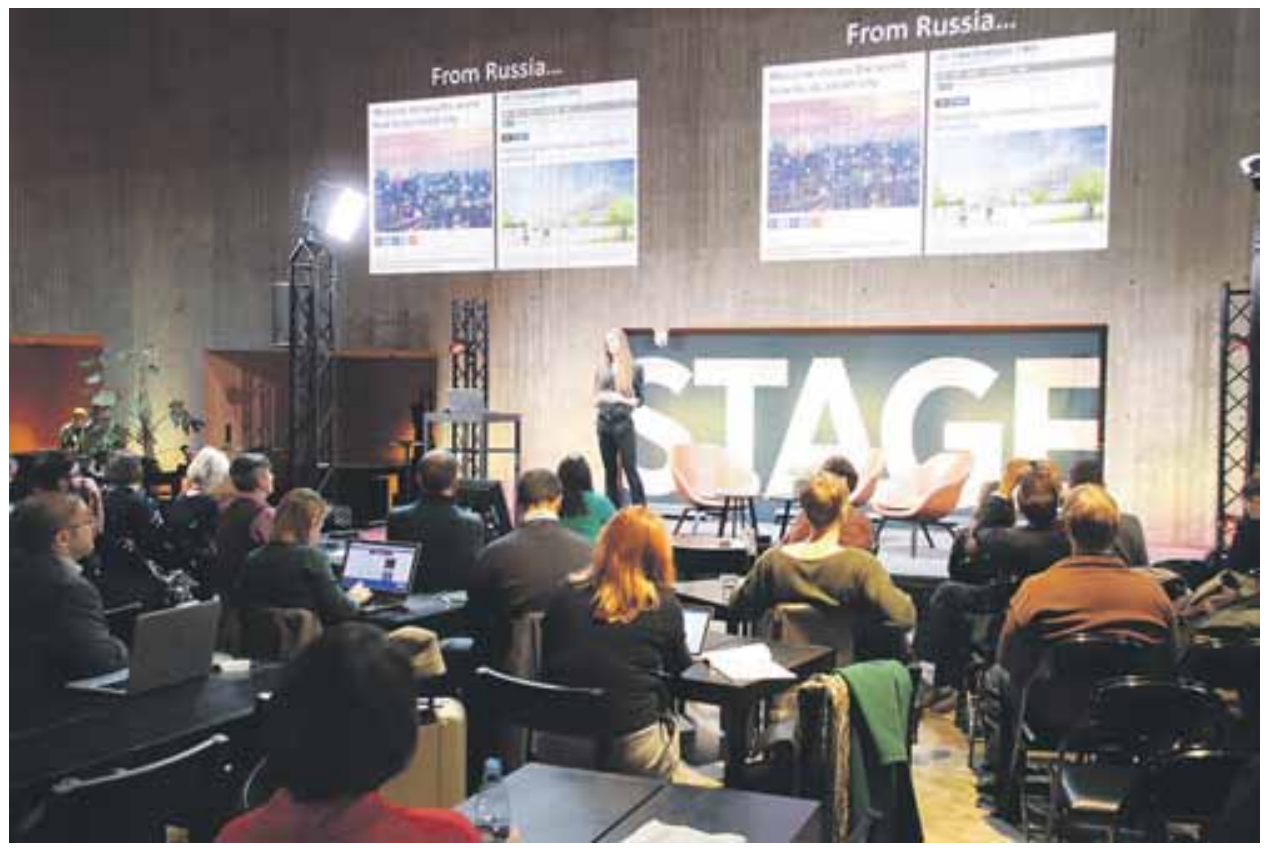

Aleksanteri-konferenssin keynotet valtasivat myös Tiedekulman Stagen. Natalie Koch (Syracuse University, USA) luennoi älykaupungeista ja teknofetisismistä Euraasian alueella. 
tulle vierailukäynnille Kansalliskirjastoon ja nauttia musiikkiesityksistä. Avainpuhujina toimivat Benjamin Peters Tulsan yliopistosta Yhdysvalloista, Anastasia Bontš-Osmolovskaja Moskovan talouskorkeakoulusta, Ellen Rutten Amsterdamin yliopistosta, Alina Sorgner Jon Cabot -yliopistosta Roomasta ja Natalie Koch Syracuse yliopistosta Yhdysvalloista. Heidän luentonsa liikkuivat Neuvostoliiton kybernetiikasta, big data -tutkimuksesta ja teknologian kulttuurihistoriallisista merkityksistä aina digitalisaation muuttuviin sukupuolipainotuksiin ja älykaupunkien tutkimukseen.

Yhdessä avainpuheenvuorot leikkasivat monipuolisella ja mielenkiintoisella tavalla koko konferenssin aihepiiriä. Toisaalta paneelisessioihin oli mahtunut kattavasti myös esimerkiksi ympäristön ja hyvinvoinnin näkökulmia teknologiaan ja digitalisaatioon. Tavallisuudesta poiketen konferenssi järjestettiin Helsingin yliopiston Metsätalossa ja Tiedekulman tiloissa, missä puheenvuoroista pääsi nauttimaan yleisöä myös konferenssin osallistujakunnan ulkopuolelta. Näistä vuosien varrella hioutuneista ja hyviksi havaituista aineksista koostuu Aleksanterikonferenssin monipuolinen konsepti.

Tänä vuonna Aleksanteri-konferessissa järjestettiin ensimmäistä kertaa posterikilpailu, jossa parhaan visuaalisen esityksen tutkimukses- taan laatinut väitöskirjantekijä palkittiin matkaavustuksella ensi vuoden konferenssiin. Arvovaltaiseen tuomaristoon kuuluivat Judith Pallot ja Markku Kangaspuro Helsingin yliopistosta sekä avainpuhujina olleet Ellen Rutten ja Alina Sorgner. Seuraavissa kappaleissa esittelemme erityisesti posterikilpailun antia, joka kuvastaa hyvin nuoremman tutkijasukupolven näköaloja Euraasian ja teknologian tarkasteluun.

Posterisessioon oli valikoitunut lopulta yhteensä seitsemän nuorta tutkijaa, joiden kaikkien töissä uuden teknologian käyttöönottoon ja digitalisaatioon liittyvät kysymykset olivat vahvasti läsnä. Johanne Kalsaasin (Bergenin yliopisto) Venäjän internet-trollausta Norjassa käsittelevä tapaustutkimus keskittyi erityisesti siihen, miten monipuolisia ja -muotoisia merkitysten verkostoja trollit rakentavat nettikeskusteluissa. Elena Hen (Moskovan talouskorkeakoulu) esitteli tutkimustaan, jossa poliitikko Valentina Matvijenkon suosion vaihtelulla pyrittiin paikantamaan Venäjän konservatiivista käännettä ja siihen liittynyttä muutosta venäläisten asennoitumisessa sukupuolten tasa-arvoon.

Sofia Hosueva (Pietarin talouskorkeakoulu) oli puolestaan Venäjän islam-enemmistöisessä Dagestanin tasavallassa suoritetussa kenttätutkimuksessaan löytänyt eroja miesten ja naisten suhtautumisessa teknologian käyttöön. Sukupuo-

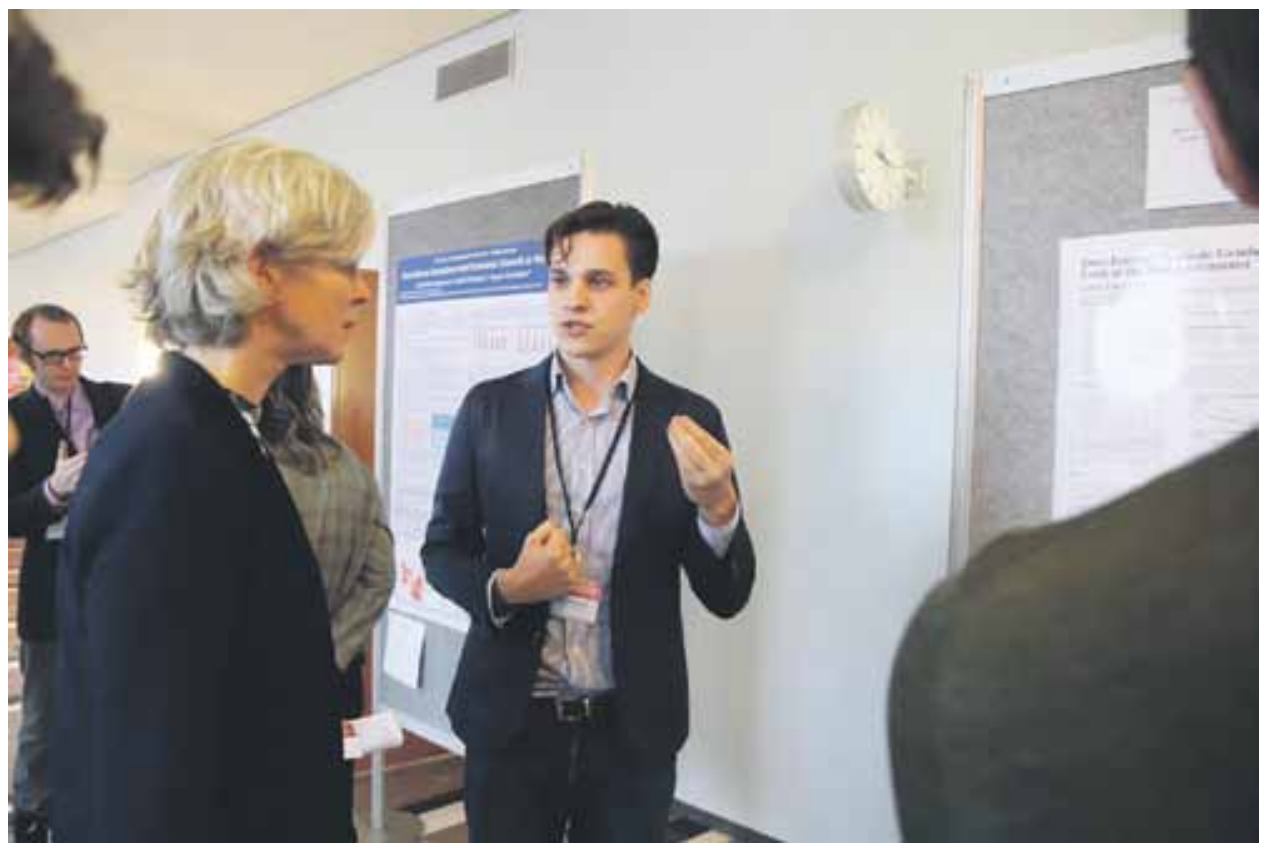

Ensimmäistä kertaa järjestetyn posterikilpailun voitti Georgy Tarasenko, joka on tilastollisin keinoin tutkinut Internetin saatavuuden ja tasa-arvon suhdetta. 
lentutkimuksen näkökulma oli esillä myös $\mathrm{Ge}$ orgyTarasenkon (Moskovan talouskorkeakoulu) tutkimuksessa, jossa tarkasteltiin Internet-yhteyden saatavuuden tasa-arvoistavia vaikutuksia jälkineuvostoliittolaisessa kontekstissa.

Natalia Kolesnikin (Venäjän tiedeakatemian sosiologian instituutti) ja Serafima Osipenkon (Venäjän presidentillinen kansantalouden ja julkishallinnon akatemia) tutkimuksissa keskiössä puolestaan olivat erilaiset uusien teknologioiden käyttöönoton vaikutukset hallinnossa ja etenkin vaaleissa. Kolesnikin tutkimus keskittyi poliittisten puolueiden vuoden 2016 vaalien yhteydessä omaksumiin uusiin viestintätyökaluihin ja niiden vaikutuksiin äänestäjien ja ehdokkaiden välisissä suhteissa. Osipenko puolestaan tarkasteli lohkoketjuteknologian käyttöönottoa julkisessa hallinnossa osana digitaalisen ekosysteemin kehittymistä ja hallinnon legitimointia.

Näiden aiheiden lisäksi myös ympäristönäkökulma oli edustettuna posterisessiossa. Nadežda Stepanova (Aleksanteri-instituutti, Helsingin yliopisto) esitteli posterissaan talouskasvun ja kasvihuonekaasupäästöjen välistä suhdetta Venäjän Jakutiassa sekä sitä, miten haja-asutus vaikuttaa sosiaalisiin, taloudellisiin ja ympäris- töhallinnallisiin prosesseihin.

Tutkimusprojektin esittäminen posterimuodossa on oma taiteenlajinsa, jolla on kuitenkin paljon annettavaa tieteen visualisoinnin ja sen myötä julkisen keskustelun näkökulmasta. Toivottavasti tämä tapahtuma järjestetään jatkossakin niin, että siitä tulee jälleen yksi Aleksanteri-konferenssin tunnusmerkki. Tämä vaikuttaisi todennäköiseltä, sillä posteriosuus keräsi paljon yleisöä ja sai myös positiivista palautetta niin osallistujilta kuin yleisöltä että tuomaristolta.

Ohjelmaan oli sisällytetty myös Helsingin yliopistossa vuonna 2018 alkaneen MARSohjelman (Master Programme of Russian Studies) toimintaa, joka lisäsi vuorovaikutusta myös yliopiston opiskelijoiden ja kansainvälisen tutkijakunnan välillä. Myös MARS-ohjelman toisen vuosikurssin opiskelijat esittelivät gradututkimustaan postereiden muodossa Tiedekulmassa keskiviikkona 23.10. Opiskelijoiden työt kattoivat laajan joukon aiheita Viron turvallistamispolitiikasta ja venäjänkielisestä TV-kanava ETV+:sta nykytanssiin Venäjällä. Monille ohjelman opiskelijoille tämä oli heidän ensimmäinen akateeminen esitelmänsä, jonka he pitivät kansainvälisen asiantuntijayleisön edessä.

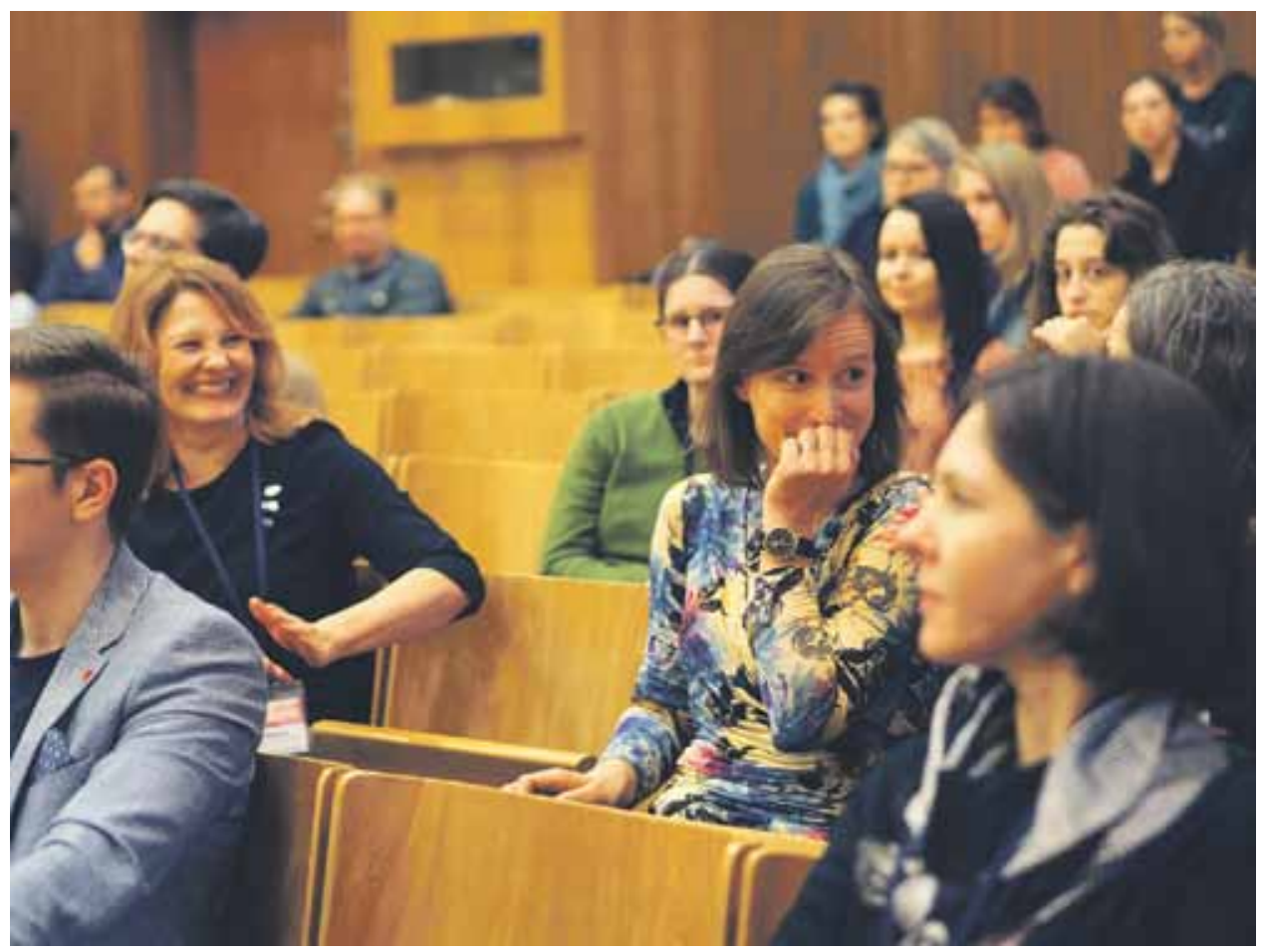

Venäjän ja Itä-Euroopan tutkimuksen seuran Idäntutkimus-artikkelipalkinnon voitti Sigrid KaasikKrogeruksen tutkimusartikkeli Viron presidenttien käyttämistä Pohjoismaa-diskursseista. 
Konferenssin päätösseremoniassa julkistettiin posterikilpailun voittaja, joka oli Georgy Tarasenko. Samalla palkinnon ansiokkaasta Idäntutkimus-lehdessä julkaistusta artikkelista VIETSin ensimmäistä kertaa järjestämässä artikkelikilpailussa pokkasi Sigrid Kaasik-Krogerus. Hänen voittaja-artikkelinsa "Kuvitellut Pohjoismaat Viron presidenttien puheissa" erottui muista ehdokkaista kilpailua tuomaroineen Arto Mustajoen mukaan uudella näkökulmalla eteläiseen naapuriimme.

Konferenssin antia yhteen vetävässä puheenvuorossaan Venäjän kielen ja kulttuurin professori Sanna Turoma (Tampereen yliopisto) nosti kysymyksen radikaaliin murrokseen tähtäävän tieteellisteknologisen mielikuvituksen, yhteiskunnan teknologisten innovaatioiden ja yhteiskuntatieteiden vuorovaikutuksesta. Hän muistutti, että fantasia- ja tieteiskirjallisuudella oli keskeinen rooli Neuvostoliitossa ja että teknologisten läpimurtojen siemenet kylvetään usein kulttuurialoilla, tieteis- ja fantasiagenreissä esiintyvien vaihtoehtoisten (usein intergalaktisten) maailmoiden muodossa. Venäläistä valtavirran fantasia- ja tieteiskirjallisuutta dominoi kuitenkin tällä hetkellä historiaan kurkottava dystopia tieteellisen ja teknologisen mielikuvituksen jäädessä vähintäänkin taka-alalle. Turoman puheenvuoro avasi kysymyksen jatkopohdinnalle siitä, missä ja miten Venäjällä ja laajemmin Euraasian alueella tulevaisuussuuntautunut tieteellistekno- loginen mielikuvitus kehittyy. Hän ehdotti, että etenkin jälkineuvostoliittolaisen post-imperiaalisen tilan marginaaleissa tapahtuvalla ylirajaisella intellektuaalisella yhteistyöllä on ensiarvoisen tärkeä rooli valtavirran arvokonservatiivisia ja uusliberalistisia käytänteitä kyseenalaistavien positiivisten tieteellisteknologisten utopioiden muodostamisessa.

Nämä pohdinnat veivät ajatukset jouhevasti tulevaisuuteen tutkimusalallamme, ja ensi vuoden konferenssiin, jonka teeman järjestelytoimikuntaa vetävä Anna-Liisa Heusala (Helsingin yliopisto) julkisti tilaisuuden päätteeksi. 2020 Aleksanteri-konferenssi tulee keskittymään globaaliin muuttoliikkeeseen ja Euraasiaan. Haku paneeli- ja esitelmäehdotuksille on auki toukokuun 15. päivään saakka ja hakujulistukseen pääsee tutustumaan tarkemmin konferenssisivuilla https://www.helsinki.fi/en/conferences/ eurasia-and-global-migration.

Joukkoon Aleksanteri-konferenssin 2019 avainpuheenvuoroista ja paneeleista tallennettuja videoita pääsee tutustumaan Aleksanteriinstituutin YouTube-kanavalla, https://www. youtube.com/user/AleksanteriInstitute

Maija Absetz, Bradley Reynolds, Elena Gorbacheva, Juulia Heikkinen, Mika Pylsy \& Saara Ratilainen Kuvat: Elena Gorbacheva ja Niina Into

\section{VIETSin Idäntutkimus-artikkelipalkinto Sigrid Kaasik-Krogerukselle}

Venäjän ja Itä-Euroopan tutkimuksen seura VIETS myönsi 18. lokakuuta 2019 Aleksanterikonferenssin päätöstilaisuuden yhteydessä tunnustukset parhaille vuosina 2017-2018 Idäntutkimus-lehdessä julkaistuille Venäjää ja Itä-Euroopan tutkimusta käsitteleville suomenkielisille tieteellisille artikkeleille. Kilpailun tuomarina toimi Venäjän kielen ja kirjallisuuden emeritusprofessori Arto Mustajoki, joka on Venäjän ja Itä-Euroopan tutkimuksen kokenut ja arvostettu asiantuntija. Parhaan artikkelin lisäksi professori Mustajoki antoi erikoismaininnat jännittävimmälle artikkelille, metodologisesti innovatiivisimmalle artikkelille ja tärkeimmälle artikkelille. Palkitut artikkelit löytyvät Idäntutkimus-lehden teemanumeroista Itämeri (2/2017), Vapaus (4/2017) ja Data/menneisyys
(3-4/2018). Julkaisemme ohessa professori Mustajoen perustelut kokonaisuudessaan.

\section{Professori Arto Mustajoen lausunto}

Useimmat arvioimani artikkelit kertovat uusista tutkimustuloksista monitieteiselle suomalaiselle lukijakunnalle. Tämä on tärkeä tehtävä, sillä se auttaa tutkijoita avartamaan omia näkemyksiään ja saamaan näin virikkeitä myös omaan tutkimukseensa riippumatta sen konkreettisesta aihepiiristä. Tekstin sopeuttamiseen lukijoiden mukaan käytetään kahta tapaa: tutkittavaa aihetta taustoitetaan tavallista laajemmin ja asioiden käsittelyssä vältetään suppeiden tutkimusalojen omaa jargonia. Mielestäni kirjoittajat ovat onnistuneet tässä useimmissa tapauksissa erin- 